\title{
Endoscopic treatment of rectovesical fistula after colorectal anastomosis: tube-in-tube endoscopic vacuum therapy method
}

A 56-year-old man underwent rectosigmoidectomy, partial cystectomy, and derivative colostomy for locally advanced distal rectal adenocarcinoma, persistent after chemoradiation. On the 25th postoperative day, he presented clinical worsening and increased abdominal drain output, and was submitted to tomography with intravesical contrast infusion, which showed a rectovesical fistula communicating with the surgical drain (> Fig. 1).

Rectoscopy showed a semi-circumferential leak of the colorectal anastomosis. Endoscopic exploration of the pelvic cavity allowed removal of clots and necrosis, and cleansing with $3 \%$ hydrogen peroxide was done. While the surgical drain was in place, tube-in-tube endoscopic vacuum therapy in the intracavitary position was performed. A guidewire was inserted through the pelvic drain and captured with a grasper. The guidewire was then used to introduce a 14-Fr Levine tube into the surgical drain. Continuous aspiration with $125 \mathrm{mmHg}$ negative pressure was started ( $\downarrow$ Video 1 ). The pump was disconnected daily so tubes could be used to irrigate the cavity [1-3].

After 10 days, a new rectoscopy showed significant reduction of leakage and the pelvic cavity, with granulation tissue formation. A full-thickness endoscopic clip was deployed, achieving complete closure of the colorectal anastomotic fistula ( Fig.2). The decision was to maintain the intracavitary tube-in-tube endoscopic vacuum therapy to drain the urinary fistula.

After another 10 days, a third rectoscopy showed sustained closure of the anastomotic fistula. An ultra-slim endoscope $(4.9 \mathrm{~mm})$ was inserted through the drain path, which was thin and long, mimicking a remaining "cystostomy." Negative pressure was turned off and a Penrose drain was left near the vesical wall.

Repeat tomography with intravesical contrast infusion 25 days later showed a
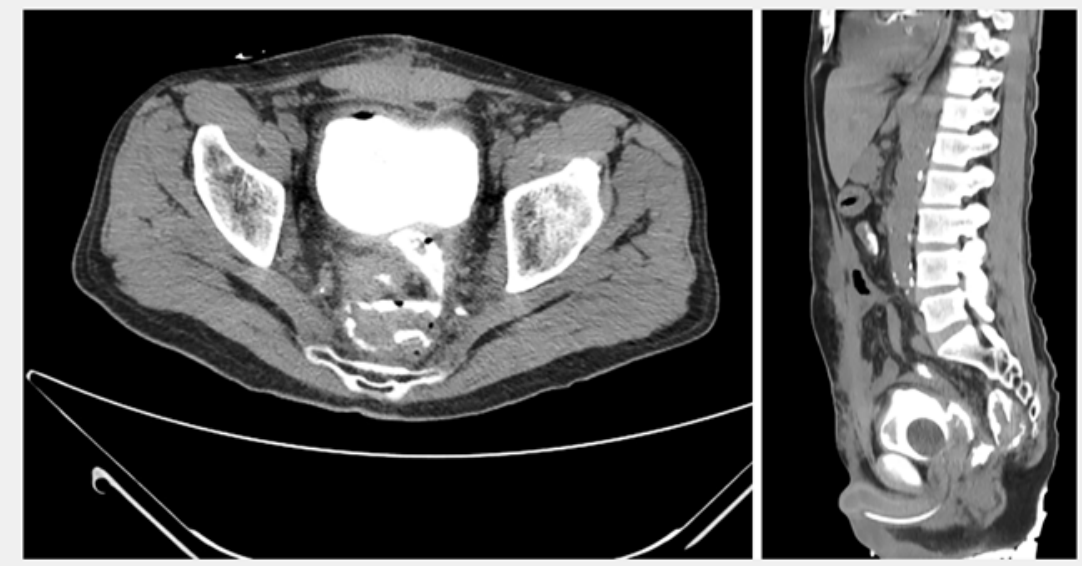

- Fig. 1 Computed tomography with intravesical contrast infusion showing rectovesical fistula communicating with surgical drain.

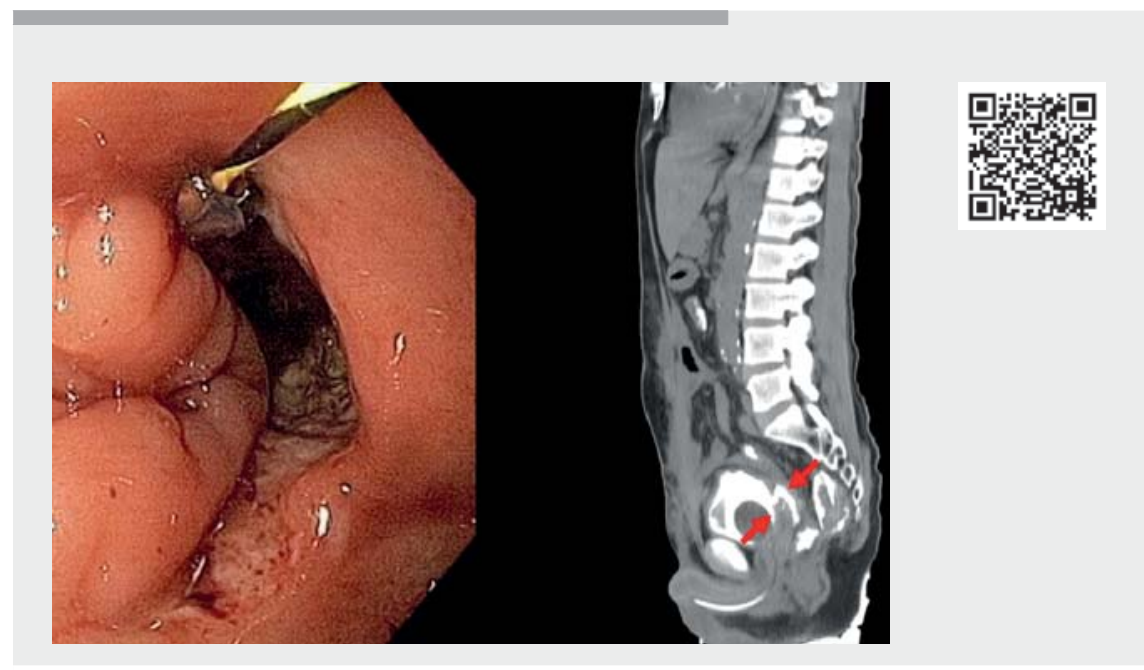

$\checkmark$ Video 1 Tube-in-tube endoscopic vacuum therapy method (TT-EVT).

well-positioned clip without extravasation of contrast. The pelvic drain was removed and the patient discharged. Control rectoscopy confirmed a defective closure and allowed reconstructive surgery.

Tube-in-tube endoscopic vacuum therapy can be done through previously placed surgical drains into the intracavitary position. It is an effective, easy-to- assemble, and low-cost treatment option even for complex digestive fistulas.

Endoscopy_UCTN_Code_TTT_1AQ_2AG

\section{Competing interests}

The authors declare that they have no conflict of interest. 


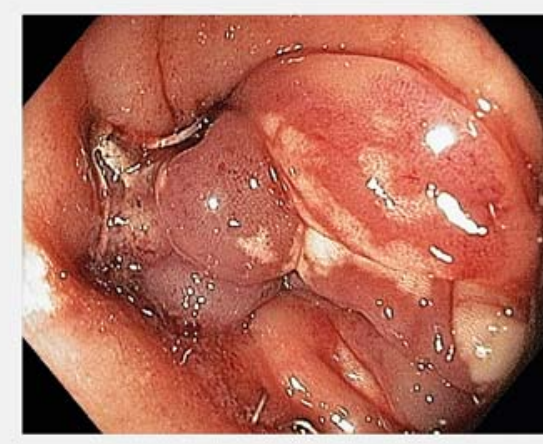

Fig. 2 Full-thickness endoscopic clip deployed, achieving complete closure of colorectal anastomotic fistula.

The authors

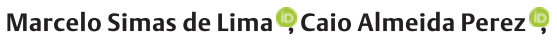

John Alexander Lata Guacho, Marcelo Mochate Flor $९$ Marina Tucci, Marina Ferreira, Fauze Maluf-Filho ${ }^{\circ}$

Department of Gastroenterology, Endoscopy Division, Cancer Institute of the University of

São Paulo, São Paulo, Brazil

\section{Corresponding author}

Caio Almeida Perez, MD

Department of Gastroenterology, Endoscopy Division, Cancer Institute of the University of São Paulo, Brazil, Av. Dr. Arnaldo, 251 São Paulo, 01246-000, Brazil

caioperez90@gmail.com

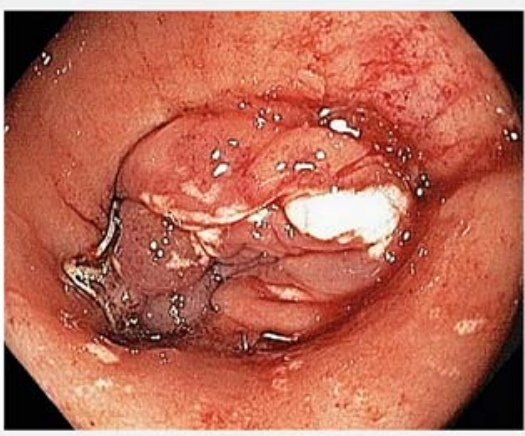

Bibliography

Endoscopy 2022; 54: E532-E533

DOI 10.1055/a-1662-5028

ISSN 0013-726X

published online 15.11 .2021

(C) 2021. Thieme. All rights reserved.

Georg Thieme Verlag KG, Rüdigerstraße 14,

70469 Stuttgart, Germany

\section{ENDOSCOPY E-VIDEOS}

https://eref.thieme.de/e-videos

口古回 Endoscopy E-Videos is an open access online section, 自: reporting on interesting cases and new techniques in gastroenterological endoscopy. All papers include a high quality video and all contributions are freely accessible online. Processing charges apply (currently EUR 375), discounts and wavers acc. to HINARI are available. Endosc Other Interv Tech 2008; 22: 1818 1825

[2] Kantowski M, Kunze A, Bellon E et al. Improved colorectal anastomotic leakage healing by transanal rinsing treatment after endoscopic vacuum therapy using a novel patient-applied rinsing catheter. Int J Colorectal Dis 2020; 35: 109-117

[3] Lima M, Lima G, Pennacchi C et al. A simple way to deliver vacuum therapy: The tube-intube endoluminal vacuum therapy modification. Endoscopy 2021; 53: E317 